\title{
Faktor-Faktor Penyebab Pengembalian Berkas Persyaratan Klaim BPJS Pasien Rawat Inap di RS PKU Muhammadiyah Yogyakarta
}

\author{
Linda Megawati ${ }^{1}$, Rita Dian Pratiwi ${ }^{2}$ \\ Prodi DIII Rekam Medis Sekolah Vokasi Universitas Gadjah Mada ${ }^{1,2}$ \\ linda.megawati@mail.ugm.ac.id ${ }^{1}$, ritadianp@ugm.ac.id ${ }^{2}$
}

\begin{abstract}
ABSTRAK
Latar Belakang: BPJS kesehatan merupakan badan hukum pemerintah untuk menyelenggarakan program jaminan sosial. Cara penagihan terhadap biaya pelayanan yaitu dengan menggunakan sistem klaim, berkas persyaratan klaim dikirimkan kepada verifikator BPJS kesehatan. Berdasarkan hasil pengamatan terdapat permasalahan yaitu terkait pengembalian berkas klaim oleh pihak verifikator BPJS.

Tujuan: Mengetahui persentase kelengkapan syarat klaim BPJS pasien rawat inap dan Mengetahui apa saja faktor penyebab dikembalikannya klaim BPJS pasien rawat inap di Rumah Sakit PKU Muhammadiyah Yogyakarta.

Metode: Survey analitik dengan pendekatan case control. Pengambilan sampel merupakan seluruh berkas klaim yang dikembalikan oleh verifikator BPJS di minggu pertama bulan maret yaitu 38 sampel (perbandingan jumlah sampel case dan control adalah 1: 1 yaitu 38 berkas kasus dan 38 berkas kontrol). Teknik pengambilan sampel menggunakan sampling jenuh.

Hasil: Hasil analisis kelengkapan terdapat beberapa berkas syarat yang tidak lengkap yaitu laporan individual pasien dengan persentase ketidaklengkapan $84 \%$. Laporan penunjang dengan persentase ketidaklengkapan $18 \%$ dan fotocopy kartu BPJS dengan persentase $7 \%$ ketidaklengkapan. Untuk mengetahui hubungan berkas tidak lengkap tersebut dengan faktor pengembalian klaim selanjutnya diuji hubungan dengan menggunakan uji statistik, dihasilkan yang memiliki $p$-value $<0,05$ berarti $\mathrm{H}_{0}$ ditolak, yaitu laporan individual pasien $\left(p\right.$-value $\left.=2,491.10^{-11}\right)$ dan laporan penunjang ( $p$ value $=0,0115$ ).
\end{abstract}

Kata kunci: kelengkapan, berkas persyaratan klaim, asuransi bpjs, pasien rawat inap.

\section{ABSTRACT}

Background: BPJS health are the agency law the government to provide social security program. Way billing about the cost of services that is by using a claim system, the required files claims delivered to verifikator bpjs health. Based on the results of observation there is a problem is that related to return claim files by the verifikator BPJS.

Purpose: know the percentage of completeness a requirement claims bpjs in-patient care and knowing what course he was returning the factors causing the claims bpjs inpatients at the hospital pku muhammadiyah yogyakarta.

Method: Survey analytic with the approach case control. The sample collection constitute a whole claim documents returned by verifikator bpjs in the first week of march that is 38 sample (comparative the sample of the case and control is 1: 1 namely 38 the case file and 38 file control of). Technique the sample collection use of sampling saturated.

Results: the results of the analysis completeness there are several file requirements that incomplete the report individual patients with the percentage incompleteness $84 \%$.Supporting report with the incompleteness $18 \%$ and fotocopy cards bpjs with the $7 \%$ incompleteness. To know relations file not complete the claims by a factor of return next tested relationship with on the $R$ Program, resulting having p-value $<0.05$ means $H_{0}$ rejected, namely report individualpatients ( $p$-value $=2,491.10^{-11}$ ) and reports supporting ( $p$-value $=0,0115$ ).

Keywords: completeness, the required files claims, insurance bpjs, inpatients 


\section{PENDAHULUAN}

Salah satu upaya yang ditempuh pemerintah dalam peningkatan kesehatan yaituadanya badan hukum yang dibentuk untuk menyelenggarakan program jaminan kesehatan masyarakat yang kemudian disebut BPJS (Badan Penyelenggara Jaminan Sosial). Permenkes No 71 tahun 2013 tentang Pelayanan Kesehatan pada Jaminan Kesehatan Nasional menyebutkan bahwa jaminan kesehatan adalah jaminan berupa perlindungan kesehatan agar peserta memperoleh manfaat pemeliharaan kesehatan dan perlindungan dalam memenuhi kebutuhan dasar kesehatan yang diberikan kepada setiap orang yang telah membayar iuran atau iurannya dibayar oleh pemerintah.

Menurut Depkes (2008) tentang petunjuk teknis administrasi klaim dan verifikasi program Jaminan Kesehatan Nasional masyarakat, bahwa kelengkapan dokumen untuk pengajuan klaim yaitu surat rujukan, pemeriksaan, pelayanan penunjang diagnostik dan tindakan medik yang telah disahkan oleh dokter yang bertanggungjawab. Berdasarkan Permenkes RI Nomor 903/Menkes/Per/2011 tentang Pedoman Pelaksanaan Program Jaminan Kesehatan Nasional Masyarakat. Apabila salah satu persyaratan tidak ada atau item-item tidak diisi dengan lengkap akan berakibat pada keberhasilan proses klaim.

Berdasarkan studi pendahuluan di RS PKU Muhammadiyah Yogyakarta dan melakukan studi dokumentasi pada bulan Desember 2015 peneliti menemukan masalah dibagian administrasi BPJS terkait berkas pengajuan klaim asuransi BPJS pasien rawat inap masih mengalami kendala, berkas klaim dikembalikan oleh verifikator BPJS Kesehatan. Hal tersebut dikarenakan ada persyaratan yang belum lengkap atau terdapat item yang tidak diisi dengan lengkap. Sehingga pihak verifikator BPJS terlebih dahulu harus mengembalikan berkas persyaratan klaim ke petugas verifikator yang berada di rumah sakit atau dokter yang merawat pasien untuk memintakan kelengkapan pengisian dokumen persyaratan tersebut. Hal tersebut dikhawatirkan akan mempengaruhi kegiatan pelayanan asuransi dan pembiayaan di RS PKU Muhammadiyah Yogyakarta.

Oleh karena itu peneliti tertarik untuk melaksanakan penelitian mengenai "Faktor-faktor penyebab pengembalian persyaratan klaim BPJS pasien rawat inap di RS PKU Muhammadiyah Yogyakarta".

\section{KAJIAN PUSTAKA}

Menurut Petunjuk Teknis, Pedoman Pelaksanaan Badan Penyelenggara Jaminan Sosial Kesehatan, Panduan Praktis Administrasi Klaim Fasilitas Kesehatan BPJS Kesehatan diajukan kepada kantor cabang/kantor operasional kabupaten/kota BPJS kesehatan secara kolektif setiap bulan dengan kelengkapan administrasi umum antara lain sebagai berikut:

a. Rekapitulasi pelayanan

b. Berkas pendukung masing-masing pasien, yang terdiri dari:

1) Surat Eligibilitas Peserta (SEP)

2) Surat perintah rawat inap

3) Resume medis yang ditandatangani oleh Dokter Penanggung Jawab Pasien (DPJP)

4) Bukti pelayanan lain yang ditandatangani oleh DPJP (bila diperlukan), misal:

a) Laporan operasi

b) Protocol terapi dan regimen (jadwal pemberian obat) pemberian obat khusus

c) Perincian tagihan rumah sakit

d) Karakterist (manual atau automatic billing)

e) Berkas pendukung lain yang diperlukan

Adapun persyaratan klaim yang dipersyaratkan Rumah sakit PKU Muhammadiyah yogyakarta sudah sesuai dengan Petunjuk Teknis, Pedoman Pelaksanaan Badan Penyelenggara Jaminan Sosial Kesehatan, Panduan Praktis Administrasi Klaim Fasilitas Kesehatan BPJS Kesehatan, yaitu antara lain:

a. SEP (Surat Eligibilitas Peserta)

b. Laporan Individual Pasien

c. Rekam Medis Laporan Penunjang Pasien

d. Resume medis 
e. Formulir Verifikasi JKN (INA CBG's)

f. Surat Keterangan (Surat perintah rawat inap, surat emergency, surat rujukan)

g. Identitas Pasien (Kartu Tanda Penduduk dan kartu BPJS)

Cara pembayaran klaim BPJS yaitu dengan sistem INA CBGs. Berdasarkan Kepmenkes Republik Indonesia Nomor 440/Menkes/SK/XII/2012 INA-CBG's merupakan singkatan dari Indonesia Case Base Groups yaitu sebuah aplikasi yang digunakan rumah sakit untuk mengajukan klaim pada pemerintah. Arti dari Case Base Groups (CBG) adalah cara pembayaran perawatan pasien berdasarkan diagnosis-diagnosis atau kasus-kasus yang relatif sama.

Sejumlah aspek yang mempengaruhi besarnya biaya INA-CBG's, yaitu diagnosa utama, adanya diagnosa sekunder berupa penyerta (comorbidity) atau penyulit (complication), tingkat keparahan, bentuk intervensi, serta umur pasien. Tarif INACBG's dibayarkan per episode pelayanan kesehatan, yaitu suatu rangkaian perawatan pasien sampai selesai. Dengan pola INA-CBG's, paket pembayaran sudah termasuk: 1) konsultasi dokter, 2) pemeriksaan penunjang, seperti laboratorium, roentgen dll, 3) obat Formularium Nasional (Fornas) maupun obat bukan fornas, 4) bahan dan alat medis habis pakai, 5) akomodasi atau kamar perawatan, 6) biaya lain yang berhubungan dengan pelayanan kesehatan pasien. Komponen biaya tersebut sudah termasuk ke dalam paket
INA-CBG's, tidak dibebankan kepada pasien.

\section{METODE PENELITIAN}

Desain penelitian kuantitatif survey analitik dengan pendekatan case control, populasi dalam penelitian ini adalah seluruh berkas klaim BPJS pasien rawat inap pada bulan januari 2016 yang dikembalikan di minggu pertama pada bulan Maret oleh verifikator BPJS ke bagian rekam medis dengan jumlah 38 kasus, sampel diambil dengan teknik sampling jenuh yaitu seluruh populasi dijadikan sampel.

Sampel berkas kontrol berjumlah 38 yaitu berdasarkan teori Budijanto (2005) sampel case dan control dapat diambil dengan perbandingan $\mathrm{N}_{1}=\mathrm{N}_{2}$. Perbandingan sampel kontrol (control) dengan sampel kasus (case) adalah $1: 1$. Dalam penelitian ini jumlah total sampel adalah 76 berkas terdiri dari 38 berkas kasus (case) dan 38 berkas kontrol (control).

\section{HASIL DAN PEMBAHASAN}

1. Persentase Kelengkapan Persyaratan Klaim BPJS Pasien Rawat Inap Di RS PKU Muhammadiyah Yogyakarta.

Berdasarkan hasil studi
dokumentasi terhadap 76 berkas klaim BPJS pasien rawat inap dengan analisis hasil perhitungan kelengkapan syarat klaim BPJS pasien rawat inap adalah sebagai berikut

Tabel 1. Hasil analisis kelengkapan berkas klaim BPJS pasien rawat inap

\begin{tabular}{lcccc}
\hline \multicolumn{1}{c}{ Item klaim BPJS } & \multicolumn{2}{c}{ Case } & \multicolumn{2}{c}{ Control } \\
\cline { 2 - 5 } & $\begin{array}{c}\text { Lengkap } \\
\mathrm{n}(\%)\end{array}$ & $\begin{array}{c}\text { Tidak } \\
\text { Lengkap } \\
\mathrm{n}(\%)\end{array}$ & $\begin{array}{c}\text { Lengkap } \\
\mathrm{n}(\%)\end{array}$ & $\begin{array}{c}\text { Tidak Lengkap } \\
\mathrm{n}(\%)\end{array}$ \\
\hline Laporan Individual Pasien & $6(16 \%)$ & $32(84 \%)$ & $35(92 \%)$ & $3(8 \%)$ \\
Resume Medis & $38(100 \%)$ & $0(0 \%)$ & $38(100 \%)$ & $0(0 \%)$ \\
Laporan Penunjang & $31(82 \%)$ & $7(18 \%)$ & $38(100 \%)$ & $0(0 \%)$ \\
Surat Eligibilitas Peserta (SEP) & $38(100 \%)$ & $0(0 \%)$ & $38(100 \%)$ & $0(0 \%)$ \\
Rekap Biaya & $38(100 \%)$ & $0(0 \%)$ & $38(100 \%)$ & $0(0 \%)$ \\
Formulir Verifikasi JKN & $38(100 \%)$ & $0(0 \%)$ & $38(100 \%)$ & $0(0 \%)$ \\
Surat Keterangan & $38(100 \%)$ & $0(0 \%)$ & $38(100 \%)$ & $0(0 \%)$ \\
Fotocopy KTP & $38(100 \%)$ & $0(0 \%)$ & $38(100 \%)$ & $0(0 \%)$ \\
Fotocopy Kartu BPJS & $34(89 \%)$ & $4(7 \%)$ & $38(100 \%)$ & $0(0 \%)$ \\
\hline
\end{tabular}


Dari hasil perhitungan analisis kelengkapan berkas syarat klaim BPJS pasien rawat inap didapatkan persentase lembar syarat tidak lengkap tersebut yaitu lembar syarat laporan individual pasien sebesar 32 lembar syarat yang tidak lengkap atau $84 \%$ atau sebanyak $6(16 \%)$ lembar syarat yang lengkap. Lembar laporan penunjang sebanyak 7 lembar syarat yang tidak lengkap atau sebesar 18\% dengan 31 (82\%) lembar syarat lengkap. Dan lembar syarat lembar fotocopy kartu BPJS sebesar 4 lembar atau $7 \%$, dan sebanyak 34 (89\%) lembar yang lengkap. Berdasarkan studi dokumentasi ketidaklengkapan syarat tersebut dikarenakan sebagai berikut

a. Laporan Individual Pasien

Lembar laporan individual pasien merupakan rekapitulasi pelayanan pasien yang merupakan lampiran yang dibuat rumah sakit yang berisi catatan perawatan pasien dalam satu episode perawatan. Senada dengan penelitian Riza (2015) menyebutkan bahwa laporan individual pasien merupakan data yang didapatkan dari dokumen persyaratan pengajuan klaim BPJS pasien rawat inap di RS PKU Muhammadiyah Yogyakarta.

Hasil studi dokumentasi terhadap 38 lembar kelengkapan syarat berkas klaim BPJS menunjukkan sebagian besar lembar laporan individual pasien klaim tidak lengkap. Dari hasil analisis dihasilkan berkas kasus (case) terdapat 32 lembar laporan individual pasien tidak lengkap dengan persentase ketidaklengkapan sebesar $84 \%$, dan berkas lengkap sejumlah 6 lembar dengan persentase $16 \%$. Pada berkas kontrol persentase ketidaklengkapan sebesar $8 \%$ atau 3 syarat tidak lengkap dan sebanyak 35 berkas lengkap atau persentase $92 \%$.

Laporan individual pasien juga dianalisis berdasarkan item kelengkapannya. Dari hasil analisis tersebut diketahui bahwa item yang menyebabkan dikembalikannya klaim BPJS yaitu antara lain Kelas Perawatan, Nomor SEP, Tanggal
Masuk, Diagnosa Utama, Diagnosa Sekunder, Prosedur, dan INA CBG's. Item yang tidak lengkap pada berkas kontrol yaitu kelas perawatan.

Dari hasil studi dokumentasi sebagian besar permasalahan yaitu karena salah dalam pengentryan item oleh petugas verifikasi BPJS internal rumah sakit. Misalnya Nomor SEP antara Nomor SEP pada laporan individual pasien dengan di lampiran lembar surat Eligibilitas Peserta (SEP) berbeda akibatnya data tidak ditemukan atau sering disebut data tidak ada (DTA), kelas perawatan pada laporan individual berbeda dengan keterangan yang ada di Lampiran SEP ataupun di lembar resume medis, tanggal masuk pada laporan individual pasien berbeda dengan tanggal masuk pada SEP, INA-CBG's karena kurang tandatanggan komite medis untuk kasus penyakit tertentu. Adapun pada item diagnosis sekunder, diagnosis primer dan tindakan/ prosedur yang menyebabkan klaim dikembalikan yaitu ketidaktepatan kode yang dikoding oleh koder.

Item pada lembar individual pasien yang memiliki persentase ketidaklengkapan paling banyak yaitu pada item diagnosa utama yaitu sebesar $26 \%$ item tidak lengkap dan $74 \%$ item lengkap dari 38 lembar case (kasus).

b. Laporan Penunjang

Laporan penunjang pasien merupakan laporan hasil pelayanan tambahan untuk pasien yang melakukan pelayanan tambahan. Hal ini sama dengan yang diungkapkan oleh Basaryadi (2013) laporan penunjang merupakan laporan dari suatu rangkaian pemeriksaan medis yang dilakukan atas indikasi tertentu guna memperoleh keterangan yang lebih lengkap. Apabila laporan penunjang tidak ada atau tidak lengkap dalam pengajuan syarat klaim BPJS pada verifikator BPJS maka akan dikembalikan untuk di lengkapi atau dilampirkan. 
Kekurangan lembar penunjang akan berpengaruh pada keabsahan penagihan dan perhitungan biaya perawatan pasien karena lembar penunjang merupakan bukti pasien telah melakukan pelayanan tambahan.

Hasil studi dokumentasi terhadap 38 lembar laporan penunjang kelengkapan syarat berkas klaim BPJS pasien rawat inap di RS PKU Muhammadiyah Yogyakarta dari hasil analisis dihasilkan terdapat 7 lembar laporan penunjang tidak lengkap dengan persentase ketidaklengkapan sebesar $18 \%$, dan berkas lengkap sejumlah 31 lembar dengan persentase $82 \%$. Berkas kontrol sudah memenuhi kriteria kelengkapan $100 \%$.

Dari hasil studi dokumentasi dihasilkan ketidaklengkapan berkas syarat laporan penunjang pasien tersebut karena tidak dilampirkannya lembar laporan penunjang pada berkas syarat pengajuan Klaim BPJS pasien rawat inap. Dan juga ditemukan kasus diagnosis pada tindakan atau prosedur yang memerlukan laporan penunjang sehingga pihak verifikator BPJS meminta kelengkapan dengan pengembalian klaim BPJS. Laporan penunjang merupakan persyaratan penting dalam pengajuan klaim BPJS. Dengan demikian pasien yang melakukan pelayanan penunjang harus disertakan atau dilampirkan bukti laporan penunjang supaya dapat diketahui kisaran biaya tambahan yang harus ditagih kepada pihak BPJS.

c. Fotocopy kartu BPJS

Kartu BPJS kesehatan merupakan tanda bukti peserta Jaminan Kesehatan Nasional (JKN) dan sebagai syarat pasien yang ditanggung biaya perawatannya oleh BPJS.

Hasil studi dokumentasi terhadap 38 lembar Fotocopy Kartu BPJS kelengkapan syarat berkas klaim
BPJS pasien rawat inap di RS PKU Muhammadiyah Yogyakarta dari hasil analisis terhadap 38 lembar kasus kelengkapan syarat berkas klaim BPJS menunjukkan lembar fotocopy kartu BPJS klaim tidak lengkap. Dari hasil analisis berkas kasus (case) terdapat 4 lembar fotocopy kartu BPJS tidak lengkap dengan persentase ketidaklengkapan sebesar $7 \%$, dan berkas lengkap sejumlah

34 lembar dengan persentase $89 \%$. Berkas kontrol sudah memenuhi kriteria kelengkapan 100\% (38).

Dari hasil studi dokumentasi penyebab ketidaklengkapan pada syarat klaim yaitu faktor fotocopy kartu BPJS karena lampiran kartu BPJS yang dilampirkan bukan kartu milik pasien melainkan kartu milik salah satu anggota keluarganya, dan kartu BPJS yang dilampirkan sudah tidak aktif. Kartu BPJS merupakan data sosial pasien. Kekurangan dalam kelengkapan fotocopy kartu BPJS bukan menjadi faktor pengembalian berkas klaim ke pihak verifikator internal rumah sakit. Kelengkapan kartu BPJS dapat dimintakan secara tertulis melalui catatan kecil yang dilampirkan beserta nomor Rekam Medis pasien kemudian catatan kekurangan Fotocopy Kartu BPJS diserahkan kebagian verifikasi interal rumah sakit untuk dilampirkan atau dilengkapi.

2. Faktor-faktor yang menyebabkan pengembalian berkas persyaratan klaim BPJS pasien rawat inap di RS PKU Muhammadiyah Yogyakarta.

Dari perhitungan kelengkapan syarat Klaim BPJS pasien rawat inap di RS PKU Muhammadiyah Yogyakarta dengan berkas syarat klaim sejumlah 76 berkas, diantaranya 38 berkas kasus (case) dan 38 berkas kontrol (control). Perhitungan menggunakan program $\mathrm{R}$ commander didapatkan hasil tiga berkas syarat klaim yang tidak lengkap yaitu diantaranya

a. Laporan individual Pasien 
Faktor-Faktor Penyebab Pengembalian Berkas Persyaratan ...

Tabel. 2 Hasil perhitungan Laporan Individual Pasien

\begin{tabular}{lllll}
\hline $\begin{array}{c}\text { Laporan Individual } \\
\text { Pasien }\end{array}$ & Ditolak & Tidak ditolak & $\begin{array}{l}\text { Odds } \\
\text { ratio }\end{array}$ & $p$-value \\
\hline Tidak Lengkap & $32(42,1 \%)$ & $3(3,9 \%)$ & 62,2222 & $2,491.10^{-11}$ \\
Lengkap & $6(7,9 \%)$ & $35(46,1 \%)$ & & \\
\hline
\end{tabular}

Dari hasil perhitungan lembar kelengkapan laporan individual pasien dengan menggunakan program $\mathrm{R}$ commander didapatkan perhitungan $p$ value sebesar $2,491.10^{-11}$ dan odds ratio sebesar 56,4546.

Dapat disimpulkan dari perhitungan kelengkapan syarat klaim BPJS dengan tingkat signifikasi $=0,05$, dan statistik penguji p_value $=2,491 \cdot 10^{-11}$. Dengan ketentuan $\mathrm{H}_{0}$ ditolak jika $\mathrm{p}_{-}$value $<$maka didapatkan hasil 2,491.10-11 < 0,05 maka $\mathrm{H}_{0}$ ditolak, berarti ada hubungan antara kelengkapan laporan individual pasien dengan dikembalikannya klaim asuransi BPJS pasien rawat inap di RS PKU Muhammadiyah Yogyakarta. Didukung dengan faktor resiko dengan hasil perhitungan odds ratio sebesar 62,22. Ketidaklengkapan berkas laporan individual pasien beresiko dikembalikan
62 kali lebih besar dibandingkan dengan lembar laporan individual pasien yang sudah lengkap.

Hal tersebut menunjukkan karena laporan individual merupakan rekapitulasi seluruh rangkaian pelayanan perawatan pasien selama di rumah sakit. Item pada laporan individual merupakan isian yang harus dilengkapi karena menunjukkan data medis dan data sosial pasien. Apabila tidak lengkap makan akan berpengaruh pada proses klaim. Jadi kelengkapan syarat laporan individual sangat berpengaruh terhadap keberasilan klaim. Hal tersebut senada dengan Malonda, Rattu dan soleman (2014) menyebutkan bahwa rekapitulasi pelayanan dan semua syarat pengajuan klaim harus dilengkapi untuk mempercepat proses klaim BPJS.

b. Laporan penunjang

Tabel. 3 Hasil perhitungan Laporan Penunjang

\begin{tabular}{lcccc}
\hline \multirow{2}{*}{ Laporan Penunjang } & \multicolumn{3}{c}{ Klaim BPJS } \\
\cline { 2 - 4 } & Ditolak & Tidak ditolak & Odds ratio & p-value \\
\hline Tidak Lengkap & $7(9,2 \%)$ & $0(0 \%)$ & 18,33 & 0,0115 \\
Lengkap & $31(40,8 \%)$ & $38(50 \%)$ & \\
\hline
\end{tabular}

Dari hasil perhitungan lembar kelengkapan laporan penunjang dengan menggunakan program $\mathrm{R}$ commander didapatkan perhitungan $p$-value sebesar 0,0115 dan odds ratio 0 (nol).

Dapat disimpulkan dari perhitungan kelengkapan syarat klaim BPJS dengan tingkat signifikasi $=0,05$, dan statistik penguji $p_{\text {-value }}=0,0115$. Dengan ketentuan $\mathrm{H}_{0}$ ditolak jika $p_{-}$value < didapatkan hasil 0,0115 $<0,05$ maka $\mathrm{H}_{0}$ ditolak, berarti ada hubungan antara kelengkapan laporan penunjang pasien dengan dikembalikannya klaim asuransi BPJS pasien rawat inap di RS PKU Muhammadiyah Yogyakarta. Didukung dengan faktor resiko dengan hasil perhitungan odds ratio sebesar 18,33. Ketidaklengkapan berkas laporan penunjang pasien beresiko dikembalikan 18 kali lebih besar dibandingkan dengan lembar laporan penunjang pasien yang sudah lengkap.

Hal tersebut menunjukkan karena laporan penunjang merupakan laporan yang berisi catatan penting dari hasil-hasil pemeriksaan atau pengobatan penunjang/tambahan berdasarkan permintaan dokter (diagnosis). Ketidaklengkapan laporan penunjang dapat mempengaruhi jumlah biaya yang ditanggungkan. Senada dengan teori Ulfah (2011) dokumen rekam medis yang lengkap seperti pemeriksaan penunjang yang digunakan dokter untuk mendukung diagnosis dan bagi koder dalam menentukan kode diagnosis sesuai 
Faktor-Faktor Penyebab Pengembalian Berkas Persyaratan ...

ICD 10 dan tindakan/prosedur sesuai ICD 9 c. Fotocopy Kartu BPJS.

Tabel. 4 Hasil perhitungan Fotocopy Kartu BPJS

\begin{tabular}{lllll}
\hline \multirow{2}{*}{ kelompok } & \multicolumn{4}{c}{ Klaim BPJS } \\
\cline { 2 - 5 } & Ditolak & $\begin{array}{c}\text { Tidak } \\
\text { ditolak }\end{array}$ & Odds ratio & p-value \\
\hline Tidak Lengkap & $4(5,3 \%)$ & $0(0 \%)$ & 0 & 0,115 \\
lengkap & $34(44,7 \%)$ & $38(50 \%)$ & \\
\hline
\end{tabular}

Dari hasil perhitungan lembar kelengkapan Fotocopy Kartu BPJS dengan menggunakan program $\mathrm{R}$ commander dengan menggunakan uji Fisher Exsact didapatkan perhitungan $p$-value sebesar 0,115 dan odds ratio sebesar 0. Dapat disimpulkan dari perhitungan kelengkapan syarat klaim BPJS dengan tingkat signifikasi $=0,05$, dan statistik penguji $p_{\text {-value }}=0,115$. Dengan ketentuan $\mathrm{H}_{0}$ ditolak jika $p_{-}$value $>$ didapatkan hasil 0,115 $<0,05$ maka $\mathrm{H}_{0}$ diterima, berarti tidak ada hubungan antara kelengkapan lembar Fotocopy Kartu BPJS dengan dikembalikannya klaim asuransi BPJS pasien rawat inap di RS PKU Muhammadiyah Yogyakarta.

Hal tersebut karena berdasarkan hasil observasi dan studi dokumentasi berkas syarat Klaim Berkas kasus, Kartu BPJS bukan merupakan faktor utama penyebab pengembalian klaim, terdapat faktor lain penyebab pengembalian klaim kartu BPJS yaitu antara lain dari empat ketidaklengkapan kartu BPJS yaitu seperti No. SEP salah, ketidaklengkapan Diagnosa utama dan diagnosa sekunder. Kekurangan dalam kelengkapan fotocopy kartu BPJS bukan menjadi faktor utama pengembalian berkas klaim ke pihak verifikator internal rumah sakit. Kartu BPJS merupakan kartu yang berisikan nomor kepesertaan BPJS dan berisi data sosial pasien. Senada dengan penelitian Ulinnuha (2014) Kartu BPJS Kesehatan sebagai tanda bukti pasien asuransi BPJS yang berisi item-item data sosial guna administrasi pasien.

\section{PENUTUP}

\section{a. Kesimpulan}

1. Kelengkapan berkas syarat klaim BPJS di RS PKU Muhamadiyah
Yogyakarta didapatkan tiga syarat klaim BPJS pasien rawat inap yang tidak lengkap pada berkas kasus (case) yaitu pada item laporan individual pasien, laporan penunjang, dan fotocopy kartu BPJS

2. Perhitungan dengan menggunakan bantuan aplikasi perhitungan statistika "R Cmdr" dapat diketahui faktor-faktor yang berhubungan dengan dikembalikannya berkas klaim pasien rawat inap di RS PKU Muhammadiyah Yogyakarta. Yaitu Laporan individual pasien dengan $P$-value $=2,491.10^{-11}$ dan Laporan penunjang dengan $p$-value $=$ 0,0115.

\section{b. Saran}

1. Mengadakan evalasi kinerja petugas klaim asuransi BPJS secara berkala mengenai kelengkapan syarat klaim dan evaluasi kepatuhan petugas dalam pengisian lembar syarat yang diajukan pada pihak verifikator BPJS. Sehingga hal tersebut dapat meminimalisir ketidaklengkapan syarat yang mengakibatkan pengembalian klaim BPJS oleh Verifikator.

2. Lembar syarat yang mempengaruhi dikembalikannya klaim BPJS pasien rawat inap di RS PKU Muhammadiyah Yogyakarta yaitu lembar laporan individual pasien dan lembar laporan penunjang. Hal tersebut dapat diteliti lebih lanjut dengan menganalisis lebih dalam untuk mengetahui faktor yang lebih 
spesifik yang mempengaruhi pengembalian klaim BPJS pasien rawat inap.

\section{DAFTAR PUSTAKA}

Huffman, E. K. (1994). Health Information Management. Illinois: Physicians records Company

Keputusan Mentri Kesehatan RI No 440/MENKES/SK/XII/2012/

tentang Sistem INA-CBG's Kesehatan [Internet].Tersedia dalam $w w w$.bpjskesehatan.go.id [Diakses 11 Januari 2016]

Malonda., Rattu \& Soleman. (2015). Hubungan Kelengkapan Dokumen Rekam Medis dengan Persetujuan Klaim Jamkesmas oleh Verifikator dengan Sistem INA CBGs di RSI Sultan Agung Semarang. Jurnal Rekam Medis.Maret 2016

Pedoman Pelaksanaan Panduan Praktis Pelayanan Kesehatan BPJS Kesehatan [Internet]. Tersedia alam www.bpjskesehatan.go.id [Diakses 10 januari 2016]

Peraturan Mentri Kesehatan Nomor 71 tentang Pelayanan Kesehatan pada Jaminan Kesehatan Nasional [Internet]. Tersedia dalam www.jkn.kemkes.go.id. [Diakses 11 Januari 2016]

Peraturan Mentri Kesehatan RI No 903/MENKES/PER/2011 tentang Pedoman Pelaksanaan Program Jaminan Kesehatan Nasional [Internet]. Tersedia dalam www.depkes.go.id. [Diakses 2 Januari 2016]

Petunjuk Teknis Administrasi Klaim Program Jaminan Kesehatan Nasional [Internet]. Tersedia dalam www.ppjk.bpjs-kesehatan.go.id [Diakses 28 Januari 2016]

Riza, Sahnur Fhaisal. (2015). Pelaksanaan klaim BPJS pasien rwat jalan di RS pelabuhan cirebon provinsi jawabarat. Karya Tulis Ilmiah (Tidak Dipublikasikan). D3 Rekam Medis UGM.

Ulfah, Siti maria., Kresnowati, Lily., \& Ernawati, Dyah. (2011). Hubungan Kelengkapan Dokumen Rekam Medis
Dengan Persetujuan Klaim Jamkesmas Oleh Verifikator Dengan Sistem INA Cbgs Periode Triwulan IV Tahun 2011 Di RSI Sultan Agung Semarang. Jurnal Rekam Medis Dan Asuransi BPJS.Maret 2016. 